\title{
Optional course «Homeopathically potentised substances: placebos or effective?» for medical students at the University of Bern, Switzerland
}

\author{
Sabine D. Klein, Martin Frei-Erb, Stephan Baumgartner, Klaus von Ammon, Ursula Wolf
}

Institute of Complementary Medicine KIKOM, University of Bern, 3010 Bern, Switzerland, http://www.kikom.unibe.ch

\section{Background}

Apart from compulsory lectures on classical homeopathy $(\mathrm{CH})$, traditional Chinese medicine/acupuncture, neural therapy and anthroposophically extended medicine (AEM), our institute at the University of Bern offers several optional practical courses for medical students.

The aim of this course during autumn 2011 and spring 2012 was to discuss basic research, observational and clinical studies in the fields of $\mathrm{CH}$ and AEM, so that students

i) learned how to read and appraise scientific publications,

ii) learned how complementary medicine can be investigated with scientific methods, and

iii) were able to form their own opinion about the possible specific effects and effectiveness of homeopathically potentised substances.

\section{Methods}

Introductory lectures on AEM, CH and study design were given to 12 second year medical students. The students appraised 12 research articles (see discussed research articles below) and presented the results in class, followed by discussions with experts in the fields of basic and clinical research from our institute. A company producing homeopathic remedies was visited and students could practise potentization procedures, both succussion (shaking) and trituration.

At the end of the course, students compiled posters with arguments in favour of and against specific effects and effectiveness as well as their own conclusions.
The course was evaluated using a written questionnaire with closed and open questions.

Results

- Previous knowledge about $\mathrm{CH}$ and AEM was scarce among the students. It slightly increased during the course, and the course fostered their interest in the topic (Figure 1).

- This course was chosen by most students, because they were genuinely interested in the topic (and not because other courses were already fully booked).

- The students especially valued the discussions, the various perspectives presented to them, and experiencing a potentization process (Table 1)

\section{Conclusion}

- Medical students were interested to learn more about homeopathically potentised substances.

- The variation in study results made it difficult for them to form their own opinion.

- Apart from appraising articles, the students would have liked to meet and talk with patients. This possibility is offered in another optional course, "Insights into complementary medical practice», including practices of $\mathrm{CH}$, AEM, traditional Chinese medicine/acupuncture and neural therapy.

Fig. 1: Answers to the closed evaluation questions $(n=10)$.

answers (percentage)

$\begin{array}{lllllllllll}0 \% & 10 \% & 20 \% & 30 \% & 40 \% & 50 \% & 60 \% & 70 \% & 80 \% & 90 \% & 100 \%\end{array}$

I was able to learn successfully in this course.

The course has encouraged my interest in the topic

The lecturers responded to questions and helped to clarify them

The content of this practical course corresponded to the announcement.

I chose this practical course, because I was interested in the topic.

I chose this practical course, because the other courses I was interested in were already fully booked.

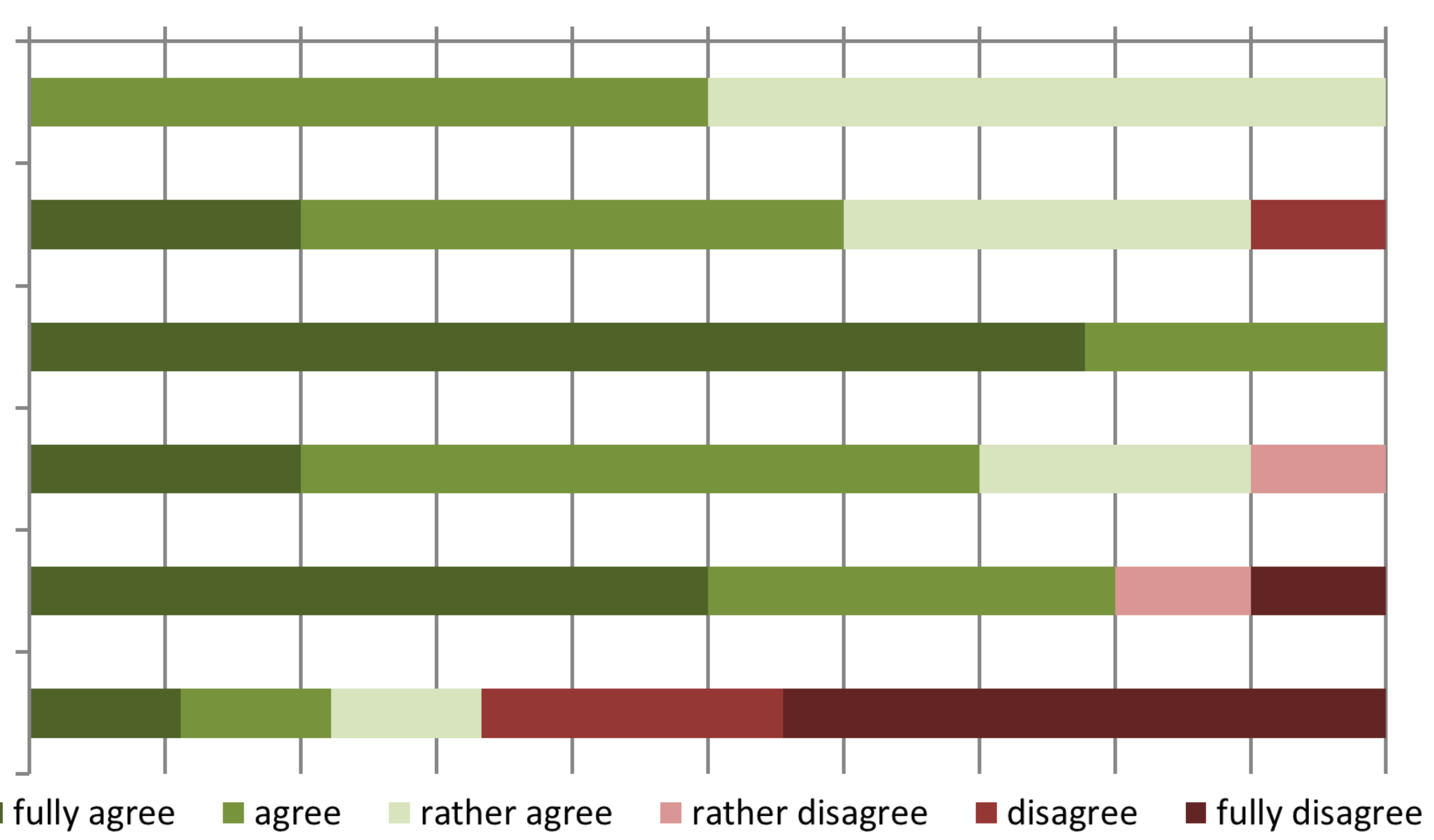

Table 1: Answers to the question: «What did you like especially about this course?»

- introductory lectures (mentioned 6 times)

- visiting company producing homeopathic remedies, potentising (5)

- interesting discussions, being able to express own opinion frankly (5)

- interesting studies, comparing various studies, learning how studies are done in complementary medicine (4)

- different views on the topic, talking to people practising homeopathy, commitment of physicist, tutors working in research and practice (4)

- liked it generally (1)

\section{Discussed research articles}

1. Belon P et al. Histamine dilutions modulate basophil activation. Inflamm Res 2004;53:181-188.

2. Betti L et al. Effect of high dilutions of Arsenicum album on wheat seedlings from seed poisoned with the same substance. Br Homeopath J 1997:86:86-89.

3. Binder $\mathrm{M}$ et al. The effects of a 45x potency of Arsenicum album on wheat seedling growth - a reproduction trial. Forsch Komplementärmed 2005;12:284-291.

4. Frass $M$ et al. Influence of potassium dichromate on tracheal secretions in critically ill patients. Chest 2005;127:936-941.

5. Frass $\mathrm{M}$ et al. Adjunctive homeopathic treatment in patients with severe sepsis: a randomized, double-blind, placebo-controlled trial in an intensive care unit. Homeopathy $2005: 94: 75-80$.

6. Frei $\mathrm{H}$ et al. Homeopathic treatment of children with attention deficit hyperactivity disorder: a randomised, double blind, placebo controlled crossover trial. Eur J Pediatr 2005;164:758-767.

7. Guggisberg AG. Replication study concerning the effects of homeopathic dilutions of histamine on human basophil degranulation in vitro. Complement Ther Med 2005;13:91-100.

8. Hamre HJ. Anthroposophic therapies in chronic disease: the anthroposophic medicine outcomes study (AMOS). Eur J Med Res 2004;9:351-360.

9. Hamre HJ et al. Anthroposophic vs. conventional therapy for chronic low back pain: a prospective comparative study. Eur J Med Res 2007;12:302-310.

10. Jacobs J et al. Homeopathy for attention-deficit/ hyperactivity disorder: a pilot randomized-controlled trial. J Altern Complement Med 2005;11:799-806.

11. Riley D et al. Homeopathy and conventional medicine: an outcomes study comparing effectiveness in a primary care setting. J Altern Complement Med 2001;7:149-159.

12. Walach H. Magic signs: a non-local interpretation of homeopathy. Br Homeopath J 2000;89:127-140. 